\title{
Influence of turning parameters on distortion of bearing rings
}

\author{
Lutz Nowag $\cdot$ Jens Sölter $\cdot$ Ekkard Brinksmeier
}

Received: 15 February 2007 / Accepted: 9 March 2007/Published online: 20 June 2007

(C) German Academic Society for Production Engineering (WGP) 2007

\begin{abstract}
The turning of bearing rings often leads to undesired form and dimensional changes after heat treatment which are referred to as distortion. In order to investigate the influence of cutting parameters on distortion, external longitudinal turning experiments were conducted. After machining the ring geometry and the residual stresses around the rings' circumference were measured. The residual stresses were then released by a subsequent heat treatment. After the heat treatment the ring geometry was measured again. The results show that the residual stresses induced by the machining process correlate well with the dimensional changes after heat treatment. The cutting parameters that have the highest influence on the dimensional changes are the feed rate and the depth of cut. Residual stresses induced by soft-machining lead to an increase of the ring diameter, depending on the machining parameters.
\end{abstract}

Keywords Production process - Turning - Distortion

\section{Introduction}

The production of metal parts consists of several manufacturing steps. Usually for high loaded workpieces a heat treatment is carried out at the end of the manufacturing process. Due to the heat treatment there is not only a desired influence on the material properties, but also very

L. Nowag · J. Sölter $(\varangle) \cdot$ E. Brinksmeier Department of Production Technology,

Manufacturing Processes, University of Bremen,

Bremen, Germany

e-mail: soelter@iwt.uni-bremen.de often an undesired change in dimension and form is apparent. These detrimental dimension and form changes are referred to as "distortion". The cause of these changes are internal stresses in the workpiece, originating from the workpiece history, as well as temperature and time dependant phase transformations and segregations in the workpiece. The machining process generates a near surface layer of plastically deformed material which acts as a source for the residual stresses over the whole workpiece cross-section [1]. These stresses have a major effect on the physical, mechanical, and chemical properties of the surface layer of the workpiece [2]. During machining plastically deformed material from previous manufacturing steps is removed which might also cause workpiece deformations [3]. In subsequent manufacturing steps, e.g. hardening, residual stresses and form deviations caused by machining can influence workpiece distortion [4, 5]. Moreover, the workpiece clamping affects the distribution of residual stresses as shown in the case of thin-walled rings $[6,7]$.

Additionally the clamping forces lead to an elastic deformation of the ring. In the case of a three-jaw-chuck a triangularity occurs after unclamping. These form deviations depend mainly on the clamping forces and on the number of jaws. Analytical formulas to calculate the form deviations are given by Wagner [8], Walter and Stahl [9], and Malluck et al. [10]. The elastic deformations due to clamping also influence chatter stability in machining [11]. Process forces also contribute to the form deviations, especially when thin walled workpieces are machined $[12,13]$.

If the form and dimensional changes exceed the tolerable limits, the workpiece has to be hard-machined after the heat treatment. As a result high costs arise. According to a survey of the VDMA (Verein des deutschen Maschi- 
nen- und Anlagenbaus/German Engineering Federation), the annual cost in 1995 for removing the distortion of parts for example in the power transmission industry in Germany amounts to 0.85 billion Euro [14].

\section{Objective and approach}

The superior aim of the investigation is to minimize the distortion of bearing rings generated by the industrial manufacturing process. The investigation can be divided into two steps. Firstly, it is important to determine the influence of soft-machining on distortion of workpieces. Secondly, the focus on a single manufacturing step of the entire process chain has to be considered. This systemoriented approach has been demonstrated by [15] for the manufacture of bearing rings. Until now it is not known how soft-machining influences the distortion of workpieces. Therefore, the objective of the work presented in this paper was to analyze the influence of turning on the distortion behavior of bearing rings made of SAE 52100 (100Cr6).

\section{Setup and design of experiments}

To determine the dimensional deviations and residual stresses generated by the machining process, rings made of SAE 52100 (100Cr6) were machined on a lathe. The rings were taken from a tube that was hot-rolled and spheroi-
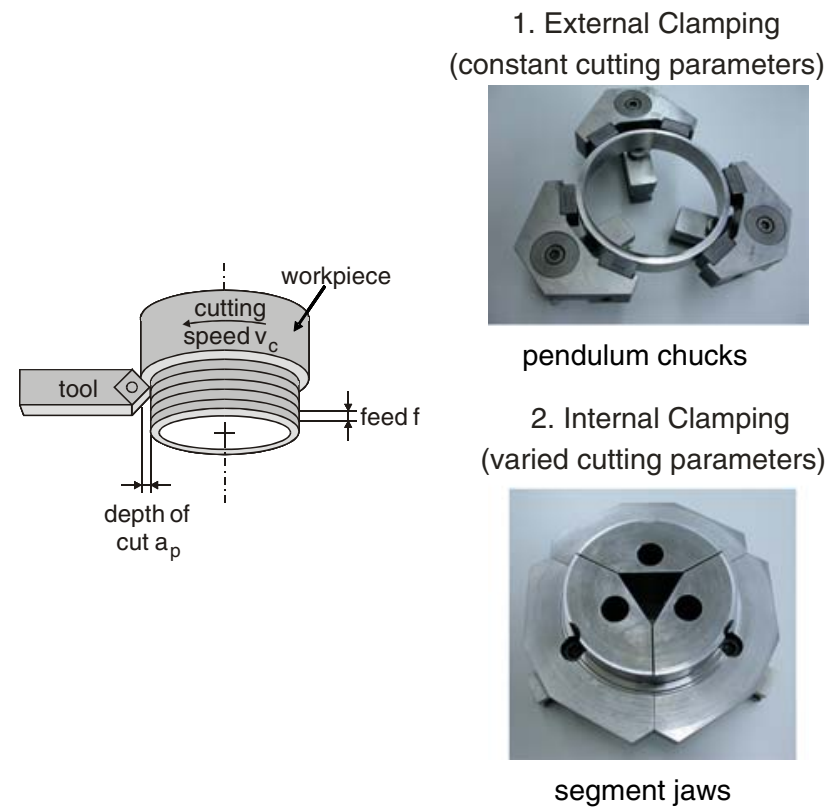

Fig. 1 Machining and clamping of the rings dized and were machined in two steps. At first they were clamped at their outer diameter with a six-jaw pendulum chuck and the rings' inner diameter was machined by longitudinal turning (Fig. 1). In a second step the rings were clamped with segment jaws at their inner circumference and their outer diameter was machined by longitudinal turning as well. The final external diameter of the rings after machining was $145 \mathrm{~mm}$ and their inner diameter $133 \mathrm{~mm}$.

For the cutting experiments one parameter was varied and the others were kept constant. Each parameter was changed on four levels (cutting speed $\mathrm{v}_{\mathrm{c}}=200,240,275$, $300 \mathrm{~m} / \mathrm{min}$, feed rate $\mathrm{f}=0.1,0.2,0.3,0.4 \mathrm{~mm}$; depth of cut $\left.\mathrm{a}_{\mathrm{p}}=0.5,0.75,1.0,1.5 \mathrm{~mm}\right)$. The constant parameter values were $\mathrm{v}_{\mathrm{c}}=240 \mathrm{~m} / \mathrm{min}, \mathrm{f}=0.4 \mathrm{~mm}$ and $\mathrm{a}_{\mathrm{p}}=0.75 \mathrm{~mm}$. If the depth of cut for the last cut was varied, the last but one cut had to be adapted too, because the sum of all four cuts had to be constant for each variation. Each experiment was realized eight times.

After machining, the form and the dimension of the rings were measured on a coordinate measurement machine and residual stresses around the rings' circumference were measured in tangential direction by using the X-ray diffraction method. The measurements were conducted at half the width around the rings' outer circumference. Subsequently the residual stresses were released by a stress relieving heat treatment and the resulting form deviations of rings were measured again. Additionally the influence of martensitic-phase transformations on the dimensional changes and form deviations were analyzed by hardening selected workpieces after machining.

The analysis of dimensional changes and form deviations was performed by means of a (fast) Fourier transform of the coordinate measurements of the rings. It transforms the spatial measurements (radii as a function of the angle) to the frequency domain returning the phase and the absolute value of the modal coefficients. The absolute values of the modal coefficients are highly important since they enable the user to separate the different influences on the out-of-roundness (Ront) of rings. The geometrical meaning of the first four modal orders are given in Table 1 . In the coordinate measurements the ring center was the origin of the coordinate system. Hence the first modal coefficient is not of importance and was neglected in the analysis.

The results of the experimental investigations will be presented in the following order: at first the influence of soft-machining with segmented jaws on the residual stress distribution is discussed. Then the effect of a variation of the machining parameters on form deviations and on dimensional changes of rings after machining, stress relieving and hardening is analyzed. 
Table 1 Geometrical meaning of modal coefficients

\begin{tabular}{lllll}
\hline Modal coefficient & 0 & 1 & 2 & 3 \\
Geometrical meaning & Radius & Displacement of the ring center & Ovality & Triangularity \\
\hline
\end{tabular}

\section{Residual stresses}

Figure 2 shows the surface residual stresses in the tangential direction of the ring. The residual stresses of the ring are varying with a periodicity of 3 around the circumference due to the clamping with segment jaws.

The reason for a varying distribution of residual stresses for the ring is described in the following. Each segment features an angle of nearly $120^{\circ}$. However, the real contact between the ring and the segment is limited to the edges of each segment when clamped. The parts of the ring that are in the middle of the segment jaws bulge out. At these positions tensile stresses at the outer circumference are higher than at other positions. For that reason there is a varying elastic stress around the circumference of the ring in the clamped state. During machining the elastic stresses are superimposed by the machining induced stresses which are approximately constant. After releasing the ring, the varying elastic stresses disappear and finally leave varying residual stresses at the surface of the ring.

\section{Form deviations of rings after heat treatment}

Figure 3 shows the first six coefficients and their mean absolute values calculated from six machined rings, three machined and stress relief annealed rings, and three machined and hardened rings. Additionally the out-of-roundness calculated according to [16] is indicated in the figure. The machined rings were clamped with segment jaws around the inner circumference. Fixing the workpiece with clamping jaws leads to elastic deformations of the ring with a periodicity of 3 . As a consequence the depth of cut along the tool path varies with this periodicity. Therefore the

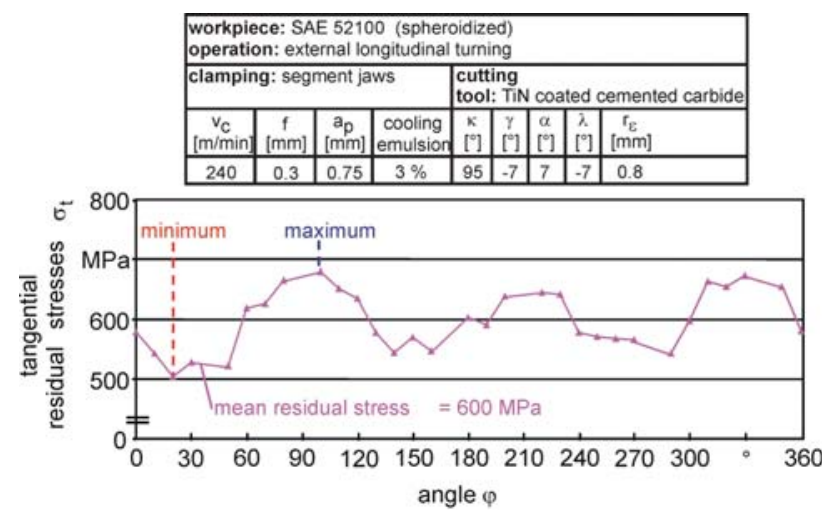

Fig. 2 Residual stress distribution around a ring's circumference out-of-roundness after machining are the result of an uneven distribution of the rings' wall thickness. It is obvious that this uneven distribution is not changed substantially by a subsequent heat treatment.

This also applies for the 2nd order Fourier coefficient (ovality) when machined and stress relief annealed rings are compared. However, hardening has a considerable effect on rings' ovality. Additionally, variations of the absolute values of the 2nd order Fourier coefficient are much higher for hardened rings. These results indicate that hardening-in particular quenching in oil-mainly affects the rings' ovality whereas triangularity is caused by the applied clamping technique in machining. The out-of-roundness of the spindle has a value of $2 \mu \mathrm{m}$ and can be neglected when analyzing the out-of-roundness caused by segment jaws.

The effect of machining parameters on the form deviations of machined workpieces is shown in Fig. 4. The variation of the feed rate $f$ had a slight effect on the form deviations of machined rings. The absolute value of the $3 \mathrm{rd}$ order Fourier coefficient increases with increasing feed rate f. Most likely this is due to the increase of the thrust and cutting force with increasing feed rate. Additionally the mean values of the measured out-of-roundness are written into the bars. However, the variation of the cutting speed and the depth of cut had no significant effect on the form deviations of rings within the analyzed parameter space.

\section{Dimensional changes of rings after heat treatment}

Induced residual stresses from machining were released by a subsequent stress relieving and hardening. Stress relieving tends to decrease the outer diameter of soft-machined rings (Fig. 5). Since soft-machining has a greater mechanical

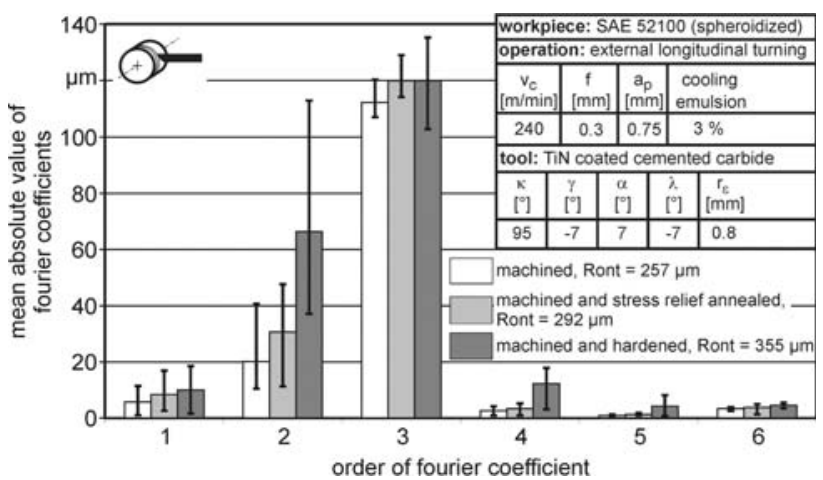

Fig. 3 Fourier coefficients of machined rings clamped with segment jaws, stress relief annealed rings and hardened rings 


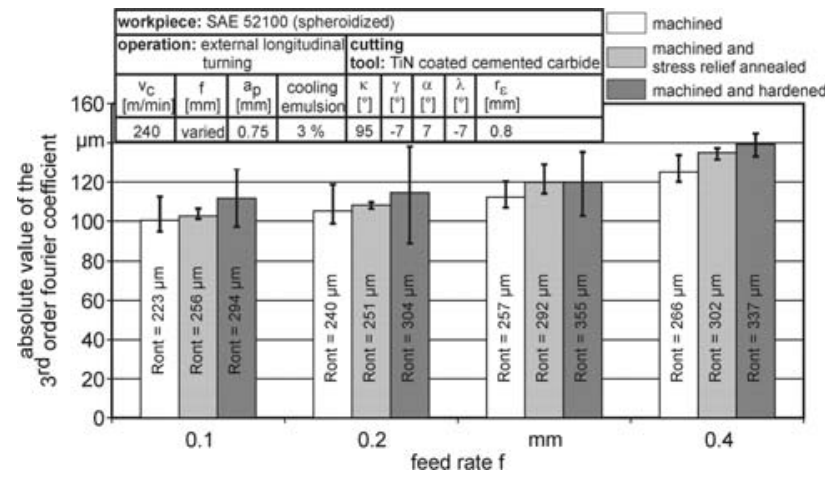

Fig. 4 Dependence of the absolute value of the 3rd order Fourier coefficient on the feed rate of machined rings clamped with segment jaws

than thermal influence compressive residual stresses prevail in the surface layer of the workpiece. During stress relieving the yield strength decreases with increasing temperature resulting in a plastic compression of the surface layer. As a consequence the outer radius decreases.

At a feed rate $\mathrm{f}=0.1 \mathrm{~mm}$ the radius change after stress relieving significantly differs from the other feed rates. It was shown in [7] that surface residual stresses after machining with feed rates of $0.2,0.3$ and $0.4 \mathrm{~mm}$ are nearly the same ( $\sim 600 \mathrm{MPa})$. For a feed rate of $0.1 \mathrm{~mm}$ the surface residual stress is significantly lower (300 MPa).

A comparison between the residual stress depth profiles for the feed rates of 0.1 and $0.4 \mathrm{~mm}$ revealed a much higher compressive load for the higher feed rate although surface residual stresses are higher. This indicates that for the dimensional change the stress depth profile has to be taken into account and that the shrinkage of the rings increases with higher compressive loads induced by soft-machining.

In contrast to that hardening leads to an increase of the workpiece radius due to the volume increase during the martensitic phase transformation. High variations of the measured radius changes originate from the quenching medium (oil). Taking this fact into account Fig. 5 suggests that using a high feed rate in soft-machining results in lower

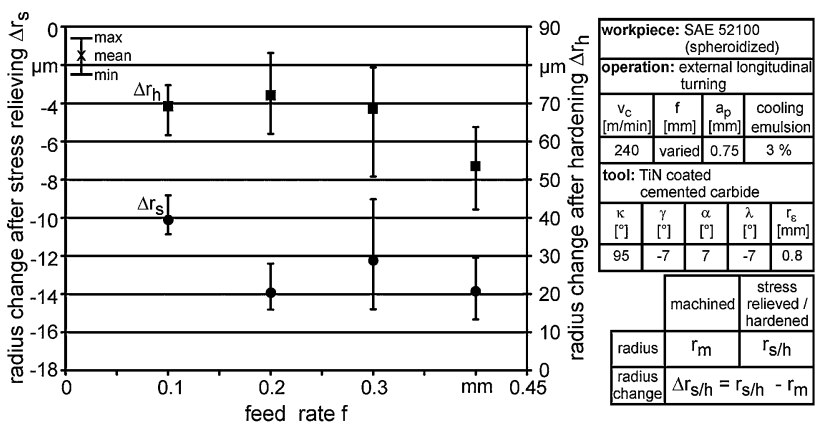

Fig. 5 Dependence of the radius change after stress relieving and hardening on the feed rate radii after hardening. As a consequence the stock removal is lower and hard-machining can be more efficient if machining parameters in soft-machining are chosen appropriately.

This conclusion can also be drawn for the variation of the depth of cut where a minimum increase of the radius can be found for a depth of cut of $0.75 \mathrm{~mm}$ (Fig. 6). A radius increase of about $80 \mu \mathrm{m}$ was found for the highest depth of cut of $1.25 \mathrm{~mm}$.

The radius change after stress relieving proportionally increases with the depth of cut. This indicates a higher compressive load for smaller depths of cuts originating from lower thermal influences during cutting. However, the absolute value of the radius change from stress relieving is quite small compared to radius changes from hardening. How the residual stress distribution after machining affects the dimensional change due to hardening is not understood yet, but is currently analyzed in the ongoing research work.

A variation of the cutting speed during soft-machining does not affect the radius change from hardening as much as the feed rate and the depth of cut do (Fig. 7). There seems to be a local minimum for a cutting speed of $\mathrm{v}_{\mathrm{c}}=240 \mathrm{~m} / \mathrm{min}$ but variations are quite high. This effect might be caused by a decreasing fraction of the heat, generated during chip formation, dissipating into the workpiece.
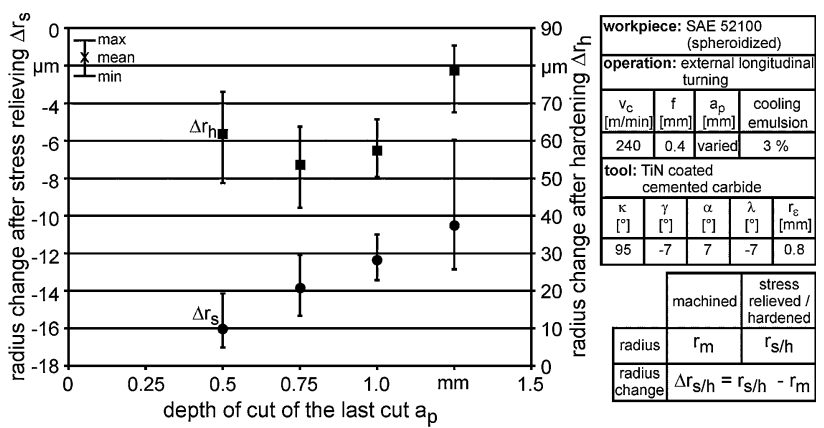

Fig. 6 Dependence of the radius change after stress relieving and hardening on the depth of cut

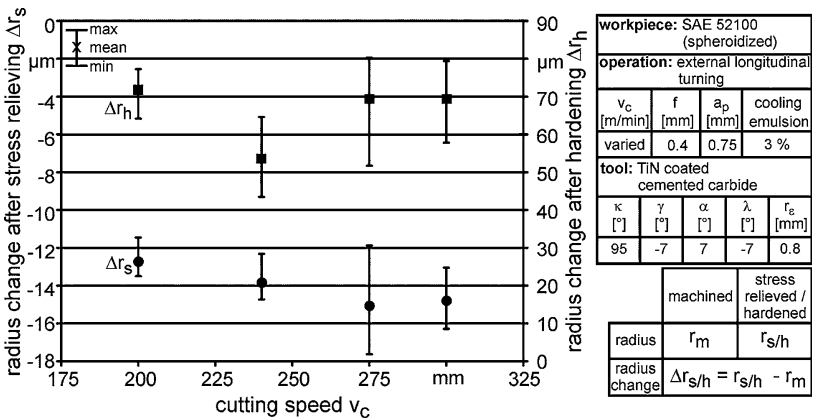

Fig. 7 Dependence of the radius change after stress relieving and hardening on the cutting speed 
As a consequence the thermal influence on the residual stress generation becomes smaller and the compressive load on the surface layer higher. However, the radius change from stress relieving is quite small and its decrease is rather a tendency than a significant effect.

\section{Conclusion and outlook}

In this paper the influence of cutting parameters on distortion of bearing rings was investigated by external longitudinal turning experiments. Clamping the ring with segment jaws leads to a varying residual stress distribution around the ring's circumference due to the elastic deformation.

The form deviation can be described by Fourier coefficients. When using segment jaws, the 3rd order coefficient, which stands for triangularity, is the highest due to the three point clamping. There is just a little effect on form deviation when varying machining parameters. An increasing effect on the 3rd order Fourier coefficient was observed when the feed rate was changed to higher values.

Residual stresses induced by soft-machining lead to an increase of the ring diameter of about $10 \mu \mathrm{m}$, depending on the machining parameters. The reason for this increase are the mechanical loads during turning which result in an elastic-plastic elongation of the surface layer. From the analyzed machining parameters the depth of cut has the most significant influence on the dimensional change of rings from stress relieving.

Hardening increases the ring diameter up to $160 \mu \mathrm{m}$ since the martensitic phase has a lower density than the spheroidized material. Although different radius changes occur with varying machining parameters the underlying mechanisms are not completely understood.

The relaxation of residual stresses during heating cannot be accounted for the increase of the diameter from hardening. Therefore, future research work has to focus on the influence of soft-machining on the microscopic effects during hardening.

Acknowledgments This work was carried out within the "Sonderforschungsbereich 570, Distortion Engineering", at the University of Bremen. The authors appreciate the financial support of the Deutsche Forschungsgemeinschaft (DFG).

\section{References}

1. Tönshoff HK (1966) Eigenspannungen und plastische Verformungen im Werkstück durch spanende Bearbeitung. Ph.D. Thesis, Universität Hannover

2. Brinksmeier E, Cammett JT, König W, Leskovar P, Peters J, Tönshoff HK (2000) Residual stresses-measurement and causes in machining processes. Annals CIRP 31(2):491-510

3. Bußmann W (1991) Formfehleranalyse beim Planfräsen gehärteter Bauteile. Ph.D. Thesis, Universität Hannover, VDIVerlag Düsseldorf

4. Volkmuth J, Lane S, Jung M, Sjöblom U (2005) Uneven residual stresses in bearing rings prior to hardening and their effect on shape changes after hardening. 1st International Conference on Distortion Engineering, Bremen, Germany, pp 23-30

5. Volkmuth J (1996) Eigenspannungen und Verzug. HTM 51(3):145-154

6. Brinksmeier E, Walter A, Sölter J, Nowag L (2003) Einfluss der Drehbearbeitung auf den Verzug von 100Cr6-Ringen. HTM 58(5):266-270

7. Sölter J, Nowag L, de Rocha A, Walter A, Brinksmeier E, Hirsch $\mathrm{T}$ (2004) Einfluss von Maschinenstellgrößen auf die Eigenspannungszustände beim Drehen von Wälzlagerringen. HTM 59(3):169-175

8. Wagner HD (1987) Spannkraftverluste beim Drehen unter Beachtung der radialen Verformung und Steifigkeit von Werkstücken. Darmstädter Forschungsberichte für Konstruktion und Fertigung, Carl Hanser Verlag München Wien

9. Walter MF, Stahl JE (1994) The connection between cutting and clamping forces in turning. Int J Mach Tools Manuf 34(7):9911003

10. Malluck JA, Melkote SN (2004) Modeling of deformation of ring shaped workpieces due to chucking and cutting forces. J Manuf Sci Eng 126:141-147

11. Rahman M (1985) Effect of clamping conditions on chatter stability and machining accuracy. Ann CIRP 34(1):339-342

12. Weinert K, Peters C, Schulte M (2002) Simulation der spanenden Bearbeitung dünnwandiger Profile. ZWF 97(12):649-651

13. Spur G, Mette U (1998) Gripping-force optimization for highspeed turning. In: Proceedings of the international seminar on improving machine tool performance, San Sebastian, vol 1, pp $151-160$

14. N. N. (1997) Technologievorsprung in der Antriebstechnik durch Leichtbau und innovative Produktionsprozesse. Forschungsantrag des VDMA ans BMBF im Rahmen des Ideenwettbewerbs für Leitprojekte zum Themenfeld "Innovative Produkte auf der Grundlage neuer Technologien". Frankfurt

15. Thoben K-D, Lübben T, Clausen B, Prinz C, Schulz A, Rentsch R, Kusmierz R, Nowag L, Surm H, Frerichs F, Hunkel M, Klein D, Mayr P (2002) "Distortion Engineering": Eine systemorientierte Betrachtung des Bauteilverzugs. HTM 57(4):276-282

16. N. N. (1985) DIN ISO 1101. Beuth-Verlag, Berlin 